\title{
Experiências educacionais no Assentamento José Eduardo Raduan: escola, educação e terra.
}

\author{
Ricardo Callegari ${ }^{1}$
}

Resumo: Busco discutir sobre a relação existente entre a luta, educação e a terra e quais os significados que estas possuem para as famílias assentadas no Assentamento José Eduardo Raduan, em Marmeleiro, Sudoeste do Paraná (1983/2003). Compreende-se que a luta feita pelos Sem Terra traz significados sobre educação e escola que se diferenciam do modelo tradicional e neoliberal de educação, principalmente por conciliar a educação com a prática e a vivência dos alunos buscando a transformação intelectual e social deste. Partindo do pressuposto que a educação é uma importante ferramenta para compreendermos o mundo em que se vive e das relações que está inserido; serve para ver a história e as lutas buscando valorizar a formação da identidade - Sem Terra - através do conhecimento destas lutas. Para tanto será analisado entrevistas orais e materiais produzidos pelo movimento.

Palavras chave: Educação no Campo; MST; Sudoeste do Paraná.

O objetivo deste trabalho é apontar experiências vividas por sujeitos sociais do campo e suas experiências com a educação no Assentamento José Eduardo Raduan em Marmeleiro, Sudoeste

\footnotetext{
1 Estudante do $4^{\circ}$ ano de história da Universidade Estadual do Oeste do Paraná, campus de Marechal Cândido Rondon. Orientador: Paulo José Koling
} 
do Paraná, no período de 1983 a 2003. Ao passo que pretendo fazer uma discussão a respeito da educação no campo e qual a sua importância num contexto de cada vez mais saída de jovens do campo para as cidades. Neste sentido, busco correlações entre o modelo neoliberal de educação e a evasão do campo por parte dos jovens. Para empreender tal análise serão analisadas entrevistas orais produzidas no ano de 2012, assim como fontes documentais que retratam a situação das escolas no Assentamento, além de discutir com referencial bibliográfico sobre o assunto como Sérgio Haddad (2008) ao debater sobre os impactos das políticas neoliberais na educação e também de Célia Regina Vendramini (2004) que evidencia a diversidade de experiências nas escolas do campo.

Parte-se do pressuposto que esses sujeitos presenciaram vivencias muito significativas para a história e para se pensar a educação, experiências essas que não se encontram apenas no âmbito da sala de aula, mas estão relacionadas com as vivências destes sujeitos nos contextos que se encontravam, como as distancias que deviam percorrer até chegar a escola, assim como as salas multisseriadas e a utilização dos espaços escolares como lugares de luta, além claro das dificuldades de estudar dado a necessidade de trabalhar conjuntamente com a família na roça. 
As motivações para tal estudo se deram através de indagações que me "perseguiam" enquanto jovem e filho de agricultor. Meus pais sempre comentavam que na "época deles", década de 70, 80 e início da década de 90, morava no campo uma enormidade de jovens, comentava ele que nos domingos enchiam dois ou três caminhões de pessoas para irem às comunidades vizinhas jogar futebol. Eram jovens, casais jovens também que se enfileiravam na luta por terra, participando de discussões, manifestações e mais tarde de ocupações para permanecer na terra.

Esta realidade muda a cada ano. Cada ano vê-se menos jovens no campo. O que devemos questionar é qual o significado que a terra assume para estes jovens, como eles - nós - vemos a terra, como esses significados foram produzidos e apontar quais os interesses envolvidos nesta dinâmica. Assim como, pensar qual o papel que a educação e as escolas têm para mudar esta realidade e o que de fato é feito.

Primeiramente é importante frisarmos que se democratizou o acesso ao ensino, mas não o conhecimento (HADDAD, 2008). De forma alguma ele é emancipador, não busca a mudança da realidade, mas sim a manutenção das estruturas e das relações sociais. E mesmo esta democratização no acesso é restrita ou limitada, pois é necessário condições para estudar, realidade que ainda não permite a todos continuarem ou iniciarem os estudos, 
Cadernos de Clio, Curitiba, n. ${ }^{\circ}$ 3, 2012

principalmente o superior, como mostram as pesquisas do MEC/Inep em que apontam para uma escolarização bruta de 15,1\% da população entre 18 e 24 anos, segundo dados de 2002.

Tanto a educação do campo, como da cidade estão inseridas num modelo que se mostra cada vez mais a favor do capital e que, por isso, não apresenta fatores fundamentais para a compreensão da desigualdade social. Esta continuada desinformação é fundamental para a manutenção da ordem vigente, pois naturaliza questões como o conflito de classes e os interesses que estão em jogo. Pretende-se desta maneira evidenciar elementos que contribuam para pensar a escola do campo, a escola do Assentamento. Partindo do pressuposto que a educação e as pessoas são transformadoras podemos ver que uma escola que situa o aluno no contexto em que está vivendo e apresenta elementos que mostram o porquê deste contexto, muito provável será sua consciência crítica a tal ponto fortalecendo a luta. Educação como disputa e conflito.

Como apontou Ramofly Bicalho dos Santos (2011), um dos fatores para que esta situação continue está relacionada, também, a condição de trabalho dos professores do campo. Por um lado, não são incentivados a desenvolver noções que possibilitem uma emancipação crítica por parte do aluno. Por outro lado, não possuem condições necessárias para preparar aulas dinâmicas, dado 
a quantidade de alunos por sala, a diversidade destes e a própria quantidade de aulas que um professor da rede pública de ensino (fundamental e médio) possui, sem contar com horas atividades suficientes para elaborar essas discussões.

Sabemos que, historicamente, existem problemas no que toca a construção de projetos que envolvem a educação do campo no Brasil. Percebemos, por exemplo, que os contratos temporários, o despreparo em lidar com os saberes da terra, o desconhecimento das diversas realidades do homem e da mulher do campo, o preconceito com o meio rural e os baixos salários geram, para as equipes, dificuldades de trabalho com os materiais didáticos produzidos para um público bem específico: as escolas das grandes metrópoles brasileiras. (SANTOS, 2011; p. 03).

Sugere-se que o capitalismo, assim como a burguesia seja ela agrária ou industrial, no seu processo de expansão se apropria de elementos os mais variados para se estruturar e expandir. Elementos que no discurso dão a impressão de que realmente mudarão algo, mas que na prática seguem os interesses da classe dominante. Esses discursos são motivados, na maioria das vezes, para neutralizar os conflitos entre burguesia e trabalhadores. Foi assim com a CLT (Consolidação das Leis Trabalhistas), com o Estatuto da Terra, com PNRA (Plano Nacional de Reforma Agrária), com o Prouni 
(Programa Universidade para Todos) e com a Reforma Universitária; são trazidos para a sociedade civil como projetos progressistas, mas que não resolvem o problema e sim o reafirmam cada vez mais.

No caso do Programa Universidade para Todos, que no discurso afirma democratizar o acesso ao ensino superior, há o investimento em faculdades ou fundações privadas, na contramão deste processo podemos perceber o sucateamento de universidades públicas com corte de verbas e falta de concursos. Este sucateamento ocorre com intuito de privatizar os espaços públicos

Com a confluência de variados aparelhos, como a mídia, educação e uso frequente de violência, busca-se "vender" estes discursos na tentativa de "anestesiar" as lutas por mudanças sociais e estruturais do sistema. O caso do Estatuto da Terra de 1964 "queria" fazer a Reforma Agrária, mas sem efetivar nenhuma desapropriação de fazendas improdutivas (MENDONÇA, 2006). Como?

Pelo I PNRA, o governo federal "pretendia" desapropriar as terras devolutas, de fazendas improdutivas e incentivar a produção. Podemos verificar, através das narrativas dos sujeitos sociais acampados na fazenda Anoni, que, desde o início, o "plano de reforma agrária" não tinha o objetivo de fazer uma transformação social nem de desapropriar as fazendas. No relato de 
Cadernos de Clio, Curitiba, n. ${ }^{\text {o } 3,} 2012$

Salete podemos verificar isso. Ao passo que ela interpreta a condição que viviam podemos perceber que a atuação do Estado se dava no sentido de expulsar, ou legitimar a expulsão, dos acampados.

Os projetos de reforma agrária conduzidos pelos governos não alteraram as estruturas de poder da classe dominante agrária pois não se efetivou uma redistribuição de terras. $\mathrm{O}$ que foi feito é o assentamento de famílias devido as formas de pressão que as famílias de Sem Terras encamparam, como as ocupações de terras e fazendas improdutivas.

Embora os governos tenham apresentado vários planos de reforma agrária estes ficaram longe de trazer significativas mudanças na estrutura agrária. Desta maneira, em um movimento contraditório, mas "programado", assentam famílias em pequenos lotes, devido as pressões dos movimentos e da sociedade civil organizada, mas sem amparar ou dispor de políticas agrícolas capazes de propiciarem condições para organização da pequena produção, não facilita o acesso aos financiamentos que ficam com juros altos. Com juros altos, sem assistência técnica capaz de organizar a propriedade, educação falha, o resultado é o endividamento dos assentados, dos pequenos produtores, pois o lote não consegue pagar o financiamento. 
É comum escutarmos que os sujeitos vendem o lote, vão se acampar novamente só para ganhar dinheiro. Como se fosse um modo de ganho fácil de vida em que a terra assume condição restrita de negócio e não de trabalho como discutido por Esterci (1990). Devemos analisar em que situações isso ocorre, primeiro por que não é um meio fácil de ganhar dinheiro e segundo por que a venda de terras é considerado pela classe dominante como algo corriqueiro, mas não em momentos de disputa com a classe trabalhadora em que esta é impossibilitada ou criminalizada por tal. No caso do Assentamento a "assistência técnica", a regularização fundiária que deixou lotes maiores e menores, que não se dão alheios as políticas e processos de expansão do agronegócio, se caracterizam como processos que impossibilitaram a permanência no campo. Estas são relações que não passam despercebidas pelos sujeitos, como fica evidente na fala de Salete Mariani:

“É, e uma das questões que a gente também não pode, não pode acusar o povo, venda de lotes. Teve venda de lotes e tem venda de lotes! A gente viveu com isso nos assentamento, aqui não é diferente. Mas a gente também não... de quem que é a culpa da venda de lote [inaudível].Por que o povo é culpado né!? Quem é que o culpado? É o movimento? Que muitos dizem: -Não, é o movimento sem terra!, mas a pessoa que 
Cadernos de Clio, Curitiba, n. ${ }^{\circ}$ 3, 2012

não quer ficar no lote ela dá um jeito. $E o$ INCRA também que... que tem essa tarefa de organizar melhor a reforma agrária também não atua, ele legaliza os lotes, não faz nada pra impedir essa venda de lote". (Salete Mariani 11/01/2012).

Deve se pensar como a venda do lote ocorre, dentro desta lógica apresentada até agora podemos perceber que fatores como a demora para a regularização dos lotes e quando regularizado feito de maneira que não distribui igualmente os lotes no mesmo tamanho para os assentados, assim como a assistência técnica que não orientou de maneira construtiva a aplicação do dinheiro liberado pelos financiamentos, esses fatores contribuíram para que os lotes de terras não se viabilizassem economicamente, desta maneira houve o endividamento de grande maioria deles. Neste âmbito que a venda de lotes deve ser analisada, inserida num contexto que não visava a permanência destes no campo.

Essa dinâmica ocasiona a venda de lotes por parte dos assentados que partem a buscar alternativas para sobreviver, uma delas é a ida para as cidades. Logo, esta não consegue "abrigar" a todos que vão aos morros, como afirma SANTOS (2011):

Outro dado relevante nesta trajetória histórica gira em torno daqueles que, no afã de procurar "uma vida melhor", partem para 
Cadernos de Clio, Curitiba, n. ${ }^{\circ}$ 3, 2012

as cidades na esperança de garantir o suficiente ao sustento individual e familiar. Nesta realidade de exclusão, estes sujeitos se deparam com o desemprego, a exploração, a corrupção e, levando ao extremo, a possibilidade de viverem como moradores de rua. Os poucos empregos encontrados são, geralmente, humilhantes e alienados. (SANTOS, 2011; p. 04).

Outro panorama que se apresenta neste contexto é a permanência das pessoas mais velhas no interior, contribuindo para o envelhecimento do campo. Esta situação está presente atualmente. Neste sentido aqueles que optam por ficar no campo encontram problemas, como a Instrução Normativa 51(IN-51) em que exige a estruturação das propriedades produtoras de leite, cobrando o uso de ordenhadeiras "balde ao pé”, resfriador de leite a granel, além da obrigatoriedade em possuir sala de ordenha.

Este modelo contribui para a inviabilidade e exclusão das propriedades familiares com pequena produção. Estas exigências se enquadram num processo de expansão do capitalismo no campo e contribuem para a transformação do modo de vida e de produção, que passa a ter uma lógica semelhante ao do agronegócio, já que incentiva uma certa "modernização" e exclui boa parte da população, transformando o modo de vida na roça em negócio. 
Neste sentido é preocupante quando vemos parcerias entre empresas privadas e transnacionais como a Syngeta, a Basf e a Monsanto, com escolas públicas. Como aponta LIMA em reportagem para o Brasil de Fato no dia 12/04/2011, "O setor (agronegócio) aposta na educação para manter sua influência, ou alienação, sobre a futura geração de trabalhadores". No caso, o autor, referia-se a cartilhas distribuídas em diversos municípios do Paraná, Rio Grande do Sul e São Paulo relacionadas ao "Projeto Agora" cuja responsabilidade é da União da Indústria de Cana de Açúcar, em que estavam presentes informações "positivas" sobre a produção do etanol, como a de que ele não compete com a produção de alimentos.

“(...) a apostila usada em sala de aula foca o desenvolvimento do setor canavieiro no Brasil e o empreendedorismo dos grandes latifundiários sob a ótica do progresso, sem apresentar aos alunos qualquer exemplo que venha desvelar contradições trabalhistas ou ambientais. A apostila não pondera, por exemplo, as contradições do trabalho escravo e a superexploração dos cortadores de cana-de-açúcar em tempos atuais. E que a monocultura e o latifúndio sempre foram avessos à diversidade produtiva" (LIMA, 2011; p. 02). 
Algo que se intensifica muito na pequena agricultura, assim como nos assentamentos, é a saída dos jovens para as cidades na busca por melhores condições do que no campo. Nem todos conseguem melhores condições, mas são incentivados a permanecer na cidade, na contramão, aqueles que permanecem no campo são apresentados a todo o momento, através da mídia e da escola (educação) para a modernidade da cidade em contraponto do atraso do campo e da pequena produção. Essas construções estão presentes desde sua infância, já que a educação ofertada na cidade não colabora para uma emancipação e formação intelectual do aluno, mas sim o direciona para o mercado de trabalho, seguindo o modelo neoliberal de educação.

Praticamente não há acesso à educação infantil ofertada pelo Estado no meio rural (...). Um tempo central e riquíssimo de possibilidades de aprendizado é ignorado e desperdiçado pelo Estado e por partes da sociedade que, culturalmente, ignora a existência da infância no campo. Seria por que a infância no campo é a infância das classes trabalhadoras?. (CALDART (org) 2006; P. 09.)

Seriam estas crianças que trabalhariam nas indústrias assim que crescerem, saindo do campo e contribuindo para a formação do 
"exército de reserva" nas cidades. É neste sentido que as escolas do campo e as escolas Itinerantes são tão importantes e fazem parte da reivindicação dos movimentos camponeses. Neste âmbito podemos afirmar e destacar que as escolas do MST estão intimamente ligadas a formação e experiência do próprio movimento, que ao longo de sua história percebeu a necessidade de lutar por novos espaços de formação política e assim se formam novos significados para a educação, para a escola e para a luta.

Neste passo, o movimento busca acompanhar e colaborar com a formação política de seus educadores, através de cursos de formação em nível médio e superior. Segundo dados coletados pelo setor de educação do MST e disponibilizados na agenda d movimento de 2004 tinham sido formados mais de 15 mil educandos até o ano referido, assim como estavam implantadas mais de 1000 escolas da $1^{\mathrm{a}}$ à $4^{\mathrm{a}}$ série e 100 escolas de $5^{\mathrm{a}}$ à $8^{\mathrm{a}}$ nos assentamentos. 1400 salas de aula, com 30 mil jovens e adultos sendo alfabetizados por 2000 educadores e educadoras. ${ }^{2}$ Podemos citar ainda as escolas Itinerantes presente em acampamentos e assentamentos, além das "Cirandas Infantis" (VENDRAMINI, 2004). A respeito da formação dos educadores é importante citarmos as parcerias com universidades no intuito de formar na área de Pedagogia da Terra para educação no campo. A própria

\footnotetext{
${ }^{2}$ Fonte: Agenda do MST, 2004.
} 
experiência e a prática política dentro dos assentamentos e acampamentos colaboram muito para a emancipação dos próprios educadores.

Vale destacar aqui a produção de materiais que podem ser utilizados nas salas de aula para pensar sobre a história do movimento, do povo e da luta por ele empreendida. Materiais como Escrevendo nossa luta, nossa história (SCHWENDLER, 2003) e A história da luta pela terra e o MST (MORISSAWA, 2001) são muito úteis e interessantes pelas discussões que trazem e pela forma didática que as empregam. No caso do primeiro contando com a participação de inúmeros assentados que contribuíram com suas vivências e experiências e o segundo que apresenta um histórico sobre a concentração de terras no Brasil, localizando o surgimento do MST como movimento de resistência e de luta por reforma agrária.

Evidenciam como a educação é um espaço de disputa ao buscarem por uma "educação de classe, massiva, orgânica ao MST, aberta para o mundo, voltada para a ação, aberta para o novo" (MORISSAWA, 2001, p, 246). Ligada inclusive ao processo de formação do movimento, construída a partir da realidade dos acampamentos e assentamentos e como processo de frequente transformação humana. 
Baseado na experiência destes sujeitos pode-se perceber sentidos e significados diferenciados a respeito da educação e das escolas. No caso do(s) assentamento(s) do MST, a formação destes significados está diretamente ligada à formação do próprio movimento e buscam conciliar a educação com a prática do aluno, não se limitando apenas a sala de aula, de forma a propiciar uma formação crítica e emancipadora.

Na luta pela terra, os Sem Terra se educam enquanto se organizam, marcham, negociam, produzem. Educam-se, também, na medida em que cultivam a memória de suas lutas, em que registram a história que constroem, em que situam suas experiências num contexto histórico mais amplo, olhando para as histórias passadas, para as conjunturas que condicionam a sua trajetória como trabalhadores que lutam pela terra (CALDART, 2000; apud SCHWENDLER, Sônia F., 2003; P. 11).

Por outro lado percebemos que com o avanço do capitalismo no campo, assim como do neoliberalismo e do agronegócio, as escolas do campo vão sendo fechadas e os alunos são retirados do campo para irem estudar na cidade. No assentamento José Eduardo Raduan esta questão está presente, o que leva os assentados a partirem para a luta seguidamente, pois as 
ameaças por parte da prefeitura para fechar as escolas são anuais, neste sentido, a organização dos assentados é fundamental para assegurarem o direito à educação, como fica evidente na narrativa de José:

Queriam fechar a escola da Barra Bonita (...), nóis imo e falemo com o prefeito, o prefeito deu uma endurecida, nós fumo de atrás, arrumemo dois ônibus de gente, fumo lá e eles se abriram tudo. Tá funcionando a escola, não sei se vai funcionar esse ano. (CALLEGARI, Ricardo. Entrevista com José (pseudônimo), 39 anos. Marmeleiro: 16 de jan. 2012, 87 min.).

O Assentamento é criado em 1998 depois da regularização dos lotes que foram conquistados mediante ocupação da fazenda Anoni em 15 de julho de 1983. A fazenda passou a ser improdutiva depois que haviam sido retiradas as madeiras da mesma. Sua área compreende cerca de 5.000 (cinco mil) hectares e se localiza no município de Marmeleiro/PR sendo limítrofe com o município de Campo Erê/SC. Nela se encontravam algumas cabeças de cavalo e em alguns lugares continha erva-mate nativa. A fazenda foi desapropriada em 1980 por decreto do Governo Federal ${ }^{3}$ para fins de Reforma Agrária ficando o Incra encarregado de distribuir e

\footnotetext{
${ }^{3}$ Decreto no 84.603 de 31 de março de 1980.
} 
Cadernos de Clio, Curitiba, n. ${ }^{\text {o }}$ 3, 2012

elaborar o projeto de Assentamento. Foram 15 anos até a regularização dos lotes, neste período as famílias se dividiram pelo interior da fazenda para poderem produzir e foram criadas, posteriormente, dez comunidades com uma escola de $1^{\mathrm{a}}$ a $4^{\mathrm{a}}$ série em cada com professores de dentro do acampamento.

As escolas não eram reconhecidas pelo município que, além de não fornecer os professores, buscava fechá-las. A questão da tirada do colégio de dentro do assentamento traz consequências para o modo de vida das famílias que ali estão, assim como para o próprio processo de construção do assentamento e de um modo de vida Sem Terra ${ }^{4}$, estando carregado de interesses políticos, econômicos e sociais por estar seguindo uma lógica neoliberal. No caso do Assentamento José Eduardo Raduan escolas foram fechadas, neste sentido, passou-se a pressionar o município a reabrilas. Forma de pressionar se dava através de comissões de dentro do assentamento, um representante de cada comunidade, em que levariam as discussões para o restante das famílias em reuniões nas comunidades. E através de reuniões desta comissão com os vereadores, prefeito, diretores e professores, como a que ocorreu no dia 13 de março de 2000, em que:

\footnotetext{
${ }^{4}$ Utilizo Sem Terra por fazer referência formação e experiência em torno da identidade dos sujeitos que estão assentados.
} 
Ficou decidido, então, nessa reunião que vai reabrir os dois núcleos no Assentamento Eduardo Raduan na comunidade de Barra Bonita e Novo Progresso. (...) com o prazo de até trinta dias, após o prazo de vinte e quatro de março, que era o prazo da comissão, para regulamentar $\mathrm{o}$ funcionamento dos núcleos e transporte. Cf. ASSENTAMENTO JOSÉ EDUARDO RADUAN. Ata de reunião. Marmeleiro/PR: $\mathrm{n}^{\mathrm{o}} 2,13 / 03 / 2000$.

Este modelo que é contestado pelo movimento se baseia em diretrizes neoliberais, numa relação que visa a formação de técnicos (mão de obra especializada) para suprir a falta de mão de obra no mercado e que transforma o ensino em mercadoria. E neste contexto se delineiam algumas prerrogativas que visam a saída do campo, principalmente dos jovens, contribuindo assim para o envelhecimento do campo. José continua:

$\mathrm{Eu}$ garanto que se o colégio fosse aqui dentro, não era um, tinha vários professores aqui dentro. Eles iam garrar amor no que eles estão fazendo. Agora vai lá e ve os professor da cidade educa os fio, eles educam pra que? A educação deles é pra voltar não pro campo, é pra ser peão. (CALLEGARI, Ricardo. Entrevista com José (pseudônimo), 39 anos. Marmeleiro: 16 de jan. 2012, 87 min.). 
Em geral as famílias que se encontram no campo têm seus filhos morando ou trabalhando na cidade, em grande parte esta mudança do campo para a cidade é motivada pelo modelo educacional vigente, pois ao se referir ao campo, não desconstrói a ideia do campo como lugar de atraso.

Neste sentido, é interessante analisarmos as comemorações "caipiras", tidas como tradicionais, geralmente nos meses de junho ou julho, quando não fazem em agosto (agostina) ou setembro (setembrina). Estas festas juninas - caso for em junho - mobilizam o colégio, tendo o envolvimento de professores, funcionários e alunos. Além, claro, de estarem aprovadas pelas secretarias de educação. Montam bingos, jogos, brincadeiras, comidas e a tradicional festa caipira em que os alunos se "vestem" de caipira, montando casais para dançar.

Podemos afirmar que esta forma de relação produz significados sobre o modo de vida camponês, estando, portanto imbricado de interesses. Ao passo que os alunos se "vestem a caráter" com roupas rasgadas, com palha de milho no bolso, geralmente com dente pintado de preto para representar a falta dele, com palavreado errôneo e barba por fazer. Produz-se uma determinada visão sobre a "vida na roça", remetendo a condições precárias de vida e de trabalho. Além disso, afirmam, legitimam e 
naturalizam vários preconceitos sobre os camponeses ou colonos e caipiras. Estes problemas são apresentados por Edilson Aparecido Chaves que evidencia "a permanência da ideia do caipira - ou aquele que o representa - como 'atrasado"' (CHAVES, 2008, p. 6).

O autor ao discutir sobre as possibilidades de utilização das músicas caipiras em aulas de história entende que "sendo a música caipira excluídas dos manuais didáticos, não houve uma contribuição no sentido da valorização desse tipo de música no âmbito escolar" (CHAVES, 2008).

Essas construções, que se dão de forma hegemônica, contribuem para que os jovens cada vez menos pretendam ficar na roça. Passam a ver o esforço que devem fazer, baseados na experiência com seus pais, para terem uma renda significativa e se voltam para as cidades, na maioria das vezes.

Dá pra contar nos dedo quanto sobraram aí. (...) $\mathrm{Na}$ verdade a gente mora aqui, mas que nem ele trabalha fora, né, eu tenho meu serviço. Se fosse tirar o sustento só daqui, que nem o pai trabalha com leite, não tem condições de se sustentar, é muito pouco. Então... a questão de trabalho, né. (CALLEGARI, Ricardo. Entrevista com Maria Joana (pseudônimo), 25 anos. Marmeleiro: 11 de jan. 2012, 102 min.). 
Porém, por exemplo, quando o MST organiza escolas Itinerantes ou luta por colégio em vários de seus acampamentos e assentamentos busca com isso apresentar uma noção de escola que não se limita a dinâmica restrita da sala de aula, por outro lado leva a escola pro acampamento na tentativa de dialogar a todo o momento com a realidade vivida pelos alunos, filhos de sem terra. Essas são noções que estão vinculadas com os significados adquiridos ao longo das experiências dentro de movimentos sociais de luta pela terra, que percebem a necessidade de lutar não apenas por terra, mas por condições de nela viver, dentro deste panorama veem na educação de suas escolas uma forma de contribuir para a (in)formação de seus militantes e dos lutadores.

Estes significados também se relacionam com a luta ao passo que veem neles um espaço conquistado pela luta e que deve ser utilizado na luta. Acrescentando assim as reuniões e discussões sobre questões pertinentes ao acampamento/assentamento com um momento de formação educacional, e se utilizam do espaço da escola para estes momentos.

A conquista da escola é um grande passo para os acampamentos e assentamentos, pois esse é tido como mais um local de disputa com a classe dominante, portanto as escolas do MST possuem um papel muito importante de formação de indivíduos preocupados com as questões do assentamento. Neste 
mesmo âmbito, podemos afirmar que as escolas são um espaço de discussões a respeito dos significados da terra, sempre na busca de valorizar os camponeses e a agricultura, assim como funcionar com uma alternativa que visa a permanência do jovem no campo.

Trata-se de pensar a terra e a educação como fundamentais para a construção de uma sociedade com justiça social e soberania alimentar. Duas questões que precisam de profundas mudanças como podemos perceber quando analisamos o modelo agrário e educacional vigente no momento. $\mathrm{O}$ primeiro baseado no agronegócio, no qual vemos constantemente trabalhadores em condições análogas as de escravo ${ }^{5}$ sendo libertos. Mesmo modelo que não produz para alimentar, mas produz para exportar, enriquecendo os grandes latifundiários, que tem no seu histórico várias mortes orquestradas de camponeses para fins de tomar a propriedade através do grilo, que é uma prática recorrente ainda nos dias de hoje. Não esquecendo dos bancos que lucram muito através da espoliação que aplicam aos pequenos agricultores com juros altíssimos nos financiamentos feitos.

\footnotetext{
${ }^{5}$ Segundo dados da CPT, mais de 35 mil pessoas foram libertas de trabalho análogo ao de escravo no Brasil nos últimos 15 anos. No Paraná, o caso mais recente envolve a Madepar indústria e comércio, e ocorreu na cidade de Palmas, sudoeste, no ano de 2011 ocasião em que foram resgatados 67 trabalhadores incluindo 5 adolescentes.
} 
Este modelo já mostrou que não é viável e nem sustentável. Podemos ver através da destruição ambiental, com o aumento de desmatamento, uso extensivo de agrotóxico e através dos transgênicos, que afetam diretamente a população quando compra estes produtos. Por outro lado beneficia empresas multinacionais e bilionárias como a Monsanto e a Bayer ${ }^{6}$ que detém o controle das sementes transgênicas (CARVALHO, 2003), fabricantes do herbicida que é utilizado nas lavouras. Dois pontos merecem discussão, a) as sementes transgênicas não se reproduzem isso acarreta no monopólio das sementes por parte de transnacionais, o que antes era de controle dos povos, passa nesta perspectiva para as mãos de empresas privadas. b) Enquanto que a utilização do "defensivo" (carinhosamente chamado desta maneira) utilizado nas lavouras transgênicas já mostrou que ao longo do tempo, as ervas daninhas criam resistência ao veneno, tendo por este motivo que destruir/queimar as plantações, pois não há mais como controlar as ervas daninhas.

Constrói-se aí um paradigma que só pode ser derrubado através de lutas sociais, pois por mais que o agronegócio se mostre contra e incapaz de proporcionar melhora nas condições de vida, acabar com a fome e/ou fazer uma transformação social, ele vem se fortalecendo cada vez mais. Pode-se perceber isso através da quase

\footnotetext{
${ }^{6}$ Empresa que fabricou o "Agente Laranja” jogado no Vietnã.
} 
constante diminuição da população camponesa, diminuição de pequenas propriedades, não separadas da lógica do capital e do neoliberalismo em financiar as grandes propriedades e através do Estado que injeta muito mais recursos financeiros para as grandes propriedades do que para a pequena produção.

O que não se coloca como novidade na história. Não só os camponeses, os operários, os trabalhadores, ou seja, os “doadores de trabalho", foram explorados pela classe dominante em vários momentos, e sempre buscaram formas de resistir e de se organizar seja nos Quilombos, nas Ligas Camponesas, em Canudos, Contestado, nas greves operárias - como os trabalhadores de hoje também buscam. Neste sentido, a luta por escolas e por outro modelo educacional deve ser considerado como forma de resistência ao passo que veem o ensino tradicional como incapaz de proporcionar uma mudança social.

Podemos afirmar que além da mídia, a educação serve de apoio para neutralizar as tensões existentes entre classes, assim como controlar a memória, difundir pensamentos elitistas e "formar" um exército de reserva alfabetizado. A este respeito é interessante percebermos a ligação entre formação e a empregabilidade, podemos perceber que a educação segue as necessidades de capitalismo e as demandas do neoliberalismo. Por isso, se tem incentivado, por parte dos governos, a implantação de 
cursos a distância que formam técnicos rapidamente para atender as demandas do mercado de trabalho.

Podemos evidenciar aqui a educação como necessitaria de mudança para passar a formar cidadãos críticos e que possam usar esta educação para sua emancipação, para que não percam sua identidade, mas que ao contrário percebam a exploração presente na sociedade e nas relações que estão inseridos, que acabam por oprimir e explorar uma determinada classe em benefício de outra. Que percebam seus inimigos e busquem através da organização coletiva resistir ao avanço do capitalismo e na defesa de um sistema mais justo, se apresenta neste âmbito, o socialismo como uma das alternativas.

Podemos concluir, com base no estudo de caso do Assentamento José Eduardo Raduan e das experiências de luta no processo de conquista da terra, que a educação é um espaço de disputa com o Estado, representado no caso pesquisado pela prefeitura que demorou em aceitar as escolas do Assentamento e que atuou no sentido de fechá-las e transferir os alunos do campo para a cidade. Estes processos exigiram a organização das famílias acampadas que passaram a pressionar o município, através de reuniões e marchas, pela regularização das escolas e depois pela permanência destas dentro do Assentamento. 
Este movimento de retirar as escolas do campo se coloca como um elemento importante e decisivo para a saída dos jovens do campo. Evidentemente que não é o único motivo, mas ao passo que distancia os conteúdos e as práticas da experiência e da realidade dos alunos contribui para perca de identificação com o campo.

Ambas as condições de trabalho - campo e cidade - estão inseridas numa lógica capitalista de produção que prioriza o grande, do pequeno; o empresário, do que o operário, trabalhador; a quantidade do que a qualidade; a quantidade, do que a condição em que é produzido. Neste sentido, a escola deve funcionar como espaço de discussão e problematização dessas questões, de forma a produzir conhecimento crítico nos alunos.

Sugere-se neste âmbito uma reformulação do próprio sistema educacional. Pois se a educação constrói sujeitos, ela também defende uma visão de mundo e um ponto de vista; com base nas direções tomadas pela educação, podemos afirmar que estas visões pertencem aos interesses da classe dominante. Desta maneira o modo de vida camponês é afetado por estas políticas, assim como toda a classe trabalhadora. 


\section{Referências Bibliográficas}

BATTISTI, Elir. “As Disputas pela Terra no Sudoeste do Paraná: os conflitos fundiários dos anos 50 e 80 do século XX" In: CampoTerritório: Revista de Geografia Agrária. v. 1, n. 2, Agosto/2006, p. 65-91;

BLOCH, Marc. Introdução à História. Lisboa: Publicações Europa-América, 1997;

BONIM, Anamaria Aimoré et alli. Movimentos Sociais no Campo. Curitiba: Scientia et Labor / Ed. Da Universidade Federal do Paraná, 1987;

BRENNEISEN, Eliane. C. Relações de poder, dominação e resistência: o MST e os assentamentos rurais. Cascavel: Edunioeste, 2002;

BURKE, Peter. Testemunha Ocular: história e imagem. Bauru, SP: EDUSC, 2004;

CALDART, Roseli Salete. Pedagogia do Movimento Sem Terra: escola é mais do que escola. Petrópolis: Vozes, 2000;

CALDART, Roseli Salete; DOLL, Johannes; PALUDO, Conceição (organizadores). Como se formam os sujeitos do campo? Idosos, adultos, jovens, crianças e educadores. Brasília: PRONERA, 2006; CARVALHO, Horacio Martins de (org.). Sementes. Patrimônio do povo a serviço da humanidade. São Paulo: Expressão Popular, 2003; 
CHAVES, Edilson Aparecido; GARCIA, Tânia Maria F. Braga. A música caipira em aulas de história: questões e possibilidades. In: ENCONTRO REGIONAL DA ASSOCIAÇÃO NACIONAL DE HISTÓRIA, 1., 2008, Jacarezinho. Anais do XI Encontro Regional da Associação Nacional de História - ANPUH/PR. Jacarezinho, 2008. p. 1-8.

CHESNEAUX, Jean. Devemos fazer tábula rasa do passado? sobre a história e os historiadores. São Paulo: Ática, 1995;

ESTERCI, Neide (apres.). Terra de Trabalho e Terra de Negócio: estratégias de reprodução camponesa. Rio de Janeiro: CEDI, 1990; FERES, João Bosco. Propriedade da Terra: opressão e miséria o meio rural na história social do Brasil. Amsterdam/Países Baixos/Holanda: CEDLA, 1990;

FREIRE, Paulo. Pedagogia da Autonomia. Rio de Janeiro: Paz e Terra, 1997;

HADDAD, Sérgio (Org.). Banco Mundial, OMC e FMI: o impacto nas políticas educacionais. São Paulo: Cortez, 2008;

HOBSBAWM, Eric; RANGER, Terence. A Invenção das Tradições. Rio de Janeiro: Paz e Terra, 1997;

IOKOI, Zilda Grícoli. Igreja e Camponeses: Teologia da Libertação e movimentos sociais no Campo - Brasil e Peru, 19641986. São Paulo: Hucitec, 1996; 
LAZIER, Hermógenes. Análise Histórica da Posse de Terra no Sudoeste Paranaense. 3. ed., Francisco Beltrão: GRAFIT Gráfica e Editora Ltda., 1998;

LEÃO, Rubem Murilo. “Tensões Sociais na Frente de Expansão: a luta pela terra no Sudoeste do Paraná - 1940/1970” In: SANTOS, José Vicente T. dos (org.). Revoluções Camponesas na América Latina. São Paulo: Ícone / Campina: Editora da UNICAMP, 1985. p. 186-228;

LIMA, Eduardo Sales de. Jornal Brasil de Fato. 12 de abril de 2011;

MARX, Karl. O Manifesto do Partido Comunista. 1951. Disponível em:

$<$ http//www.scielo.com/marx/>. Acesso em: 07 de janeiro de 2009; MARTINS, José de Souza. A Chegada do Estranho. São Paulo: Hucitec, 1993;

; Expropriação \& Violência: a questão política no campo.

2. ed., São Paulo: Hucitec, 1982;

; José de Souza. Fronteira: a degradação do Outro nos confins do humano. São Paulo: Hucitec, 1997;

MENDONÇA, Sonia Regina. A Classe Dominante Agrária: natureza e comportamento - 1964-1990. São Paulo: Expressão Popular, 2006;

MORISSAWA, Mitsue. A história da luta pela terra e o MST. 21 edição. São Paulo: Expressão Popular, 2001; 
PEGORARO, Éverly. Dizeres em Confronto: a Revolta dos Posseiros de 1957 na Imprensa Paranaense. Guarapuava: Editora UNICENTRO, 2008;

PERROT, Michelle. Os Excluídos da História - operários, mulheres e prisioneiros. Rio de Janeiro: Paz e Terra, 1988;

POLLAK, Michel. Memória, Esquecimento e Silêncio. In: Estudos Históricos. Rio de Janeiro: FVG, vol. 2, n. 3, 1989, p. 3-15;

RICOEUR, Paul. A Memória, a História, o Esquecimento. Campinas/SP: Editora da UNICAMP, 2007;

ROSSETTO, Edna. A educação das crianças pequenas nas cirandas infantis do MST. In: Revista Múltiplas Leituras, v. 3, n. 1, 2010, p. 103-118;

SALGADO, Sebastião. Terra. São Paulo: Companhia das Letras, 1997;

SANTOS, Ramofly Bicalho dos. A educação do campo e o ensino de história: possibilidades de formação. In: Revista Percursos. Florianópolis, vol. 12, n. 01, 2011, p. 183 - 196;

SCHREINER, Davi Félix. Entre a Exclusão e a Utopia: um estudo sobre os processos de organização da vida cotidiana nos assentamentos rurais (Região Sudoeste/Oeste do Paraná). São Paulo: USP/Programa de Pós-Graduação em História Social, 2002. (Tese de Doutorado em História). 
SCHWENDLER, Sônia Fátima; VARGAS, Maria Cristina (organizadores). Escrevendo nossa luta, nossa história. 20. ed., Curitiba: Editora Gráfica Popular, 2003; STÉDILE, João Pedro (coord.). A Questão Agrária Hoje. 3. ed., Porto Alegre: ed. Universidade/UFRGS, 2002;

THOMPSON, E. P. Costumes em Comum: estudos sobre a cultura popular tradicional. 3. reimpressão, São Paulo: Companhia das Letras, 1998;

VENDRAMINI, Célia Regina. A escola diante do multifacetado espaço rural. Perspectiva, v. 22, n. 01, p. 145-165, 2004;

VIEIRA, Maria do Pilar (org.). A pesquisa em História. São Paulo: Ática, 1998;

WACHOWICZ, Ruy Christovam. Obrageros, mensus e colonos: História do Oeste do Paraná. 2 ed., Curitiba: Ed. Vicentina, 1987a.

\section{Fontes:}

CALLEGARI, Ricardo. Entrevista com José (pseudônimo), 39 anos. Marmeleiro: 16 de jan. 2012, 87 min.;

CALLEGARI, Ricardo. Entrevista com Maria Joana (pseudônimo), 25 anos. Marmeleiro: 11 de jan. 2012, 102 min.

ASSENTAMENTO JOSÉ EDUARDO RADUAN. Ata de reunião. Marmeleiro/PR: ${ }^{\circ}{ }^{2}, 13 / 03 / 2000$ 